\title{
ESTIMATION OF COOLING LOAD OF OFFICE BUILDINGS OF BAYERO UNIVERSITY KANO
}

\author{
${ }^{1 *}$ Ibrahim Usman Haruna, ${ }^{2}$ Ibrahim Ahmad Rufai, ${ }^{3}$ Dalhatu Balarabe Yahaya \\ ${ }^{1}$ Department of Mechanical Engineering, Federal Polytechnic Mubi, Adamawa State, Nigeria \\ ${ }^{2,3}$ Department of Mechanical Engineering, Bayero University Kano, Kano State, Nigeria
}

Corresponding author: Email heldabuk@yahoo.com; Phone. No. +2348031165647

\begin{abstract}
Estimation of building cooling load is of critical importance for achieving energy efficiency and thermal comfort in buildings. The computer-based methods for cooling load estimation are expensive while most of the inverse models are complex and require adequate time to train the models. In this paper, a multiple linear regression model was developed using the concept of Taguchi orthogonal array. The model developed has high performance based on the computed $R^{2}$. The cooling load model developed was validated using EnergyPlus thermal simulation. Employing the cooling load model, the cooling load of the site office building was $10.48 \mathrm{~kW}$ while the EnergyPlus simulated result was $10.29 \mathrm{~kW}$. The RMSLE between the predicted and the EnergyPlus simulated result is 0.017 which indicates that the model developed has high predictive power. The proposed model has high inference and prediction powers and could be used for predicting cooling load of office buildings of Bayero University Kano (BUK) or any other building with similar attributes.
\end{abstract}

Keywords: Building cooling load; Prediction model; office building; regression analysis, Taguchi analysis

\section{Nomenclature}

$Q_{s}=$ Sensible heat released by adult male

$\dot{Q}_{\text {lat }}^{p p l}=$ Latent cooling load from occupants

$\dot{Q}^{p p l}=$ Sum of heat gain from occupants

$Q_{s}=$ Sensible heat released by adult male

$\dot{Q}_{\text {lat }}^{\text {pl }}=$ Latent cooling load from occupants

$\dot{Q}^{p p l}=$ Sum of heat gain from occupants

$Q_{s}=$ Sensible heat released by adult male

$\dot{Q}_{\text {lat }}^{\text {ppl }}=$ Latent cooling load from occupants

$\dot{Q}^{p p l}=$ Sum of heat gain from occupants

$Q_{s}=$ Sensible heat released by adult male

$\dot{Q}_{\text {lat }}^{p p l}=$ Latent cooling load from occupants

$\dot{Q}^{p p l}=$ Sum of heat gain from occupants

$Q_{s}=$ Sensible heat released by adult male

$\dot{Q}_{\text {lat }}^{p p l}=$ Latent cooling load from occupants

$\dot{Q}^{p p l}=$ Sum of heat gain from occupants

$Q_{s}=$ Sensible heat released by adult male

$\dot{Q}_{l a t}^{p p l}=$ Latent cooling load from occupants

$\dot{Q}^{p p l}=$ Sum of heat gain from occupants

$Q_{s}=$ Sensible heat released by adult male

$\dot{Q}_{\text {lat }}^{p p l}=$ Latent cooling load from occupants

$\dot{Q}^{p p l}=$ Sum of heat gain from occupants

$Q_{s}=$ Sensible heat released by adult male

$\dot{Q}_{l a t}^{p p l}=$ Latent cooling load from occupants

$\dot{Q}^{p p l}=$ Sum of heat gain from occupants

$Q_{S}=$ Sensible heat released by adult male

$\dot{Q}_{\text {lat }}^{p p l}=$ Latent cooling load from occupants
$\dot{Q}_{\text {total }}^{p p l}=$ Total heat gain from occupants

$\dot{Q}_{\text {lighting }}=$ Heat gain from lighting

$W_{b}=$ Wattage of the bulb

$F_{U L}=$ Lighting use factor

$F_{S A}=$ Special ballast allowance factor

$\dot{Q}_{\text {equipment }}=$ Heat gain from equipment

$P_{e}=$ Power rating of equipment/appliance

$E_{m}=$ Efficiency of motor

$F_{L M}=$ Motor load factor

$F_{U M}=$ Motor use factor

$P_{t}=$ Summation of power ratings of equipment

$\dot{Q}_{\text {total }}^{\text {equip }}=$ Total heat gain by equipment

$\dot{Q}_{s e n}^{\text {infil }}=$ Sensible load of infiltration

$A C H=$ Air change hour

$\dot{V}=$ Flow rate of outdoor air into the room

$\rho_{a i}=$ Density of air at indoor temperature

$\rho_{a o}=$ Density of air at outdoor temperature

$C_{p o}=$ Specific heat capacity of outdoor air

$C_{p i}=$ Specific heat capacity of indoor air

$\dot{Q}_{\text {lat }}^{\text {infil }}=$ Latent heat load of infiltration

$h_{f g}=$ Latent heat of vapourization

$\omega_{i}=$ Absolute humidity of indoor air

$\omega_{o}=$ Absolute humidity of outdoor air

$R^{2}=$ Coefficient of determination

$V I F=$ Variance inflation factor 


\section{Introduction}

The building sector is the leading energy consumer by consuming about $40 \%$ of world's total energy and represents about $30 \%$ contributors of global Greenhouse Gas emission [1-3]. A larger proportion of the energy consumed in the building sector is used for the provision of thermal [4].

The cooling load of a building is the amount of heat energy that must be removed from a space to maintain the parameters (temperature, relative humidity, and air velocity) within the acceptable comfort range [5]. According to [5] and [6], the determination of building cooling load is a prerequisite for rightsizing a building cooling system. The researcher [7] stated that an inaccurate estimation of building cooling load causes waste of energy due to the use of an oversize system or sacrificing thermal comfort due to the use of undersize cooling system.

The building cooling loads are determined using two different approaches, namely: the forward or classical approach and the inverse or data-driven approach [8].. According to [9], a forward or classical approach requires detailed building information and the use of physical principles to characterize building thermal performance. The classical approach of building cooling load estimation can be traditional or computerbased. According to [5], the traditional method includes the following: heat balance (HB) method, transfer function method (TFM), etc. The difficulty in solving unsteady equations with unsteady or dynamic boundary conditions rendered the traditional method unpopular. Some studies stated that the use of simulation software for building cooling load prediction is costly [10-12].

The inverse models include linear and non-linear models [7]. The researcher [12] gave examples of linear models to include: multiple linear regression (MLR), autoregressive (AR), etc. The regression models predict building cooling load by determining the appropriate coefficients that are associated with the most influential inputs [11]. According to [11], MLR is the most commonly used regression model for the prediction of building cooling load because of its direct and simplified nature. Numerous researchers had employed the MLR model to predict building cooling load and energy consumption [13-19]. The non-linear data-driven models include the Artificial Neural Network (ANN), support vector machine (SVM) etc [20], and are complex because of the difficulty of the models to converge to an optimal solution [11].

To this end, this paper therefore attempts to develop a cooling load prediction model for office buildings of Bayero University Kano (BUK) using Taguchi orthogonal array and multiple linear regression method.

\section{Study Area Description}

The characteristics of the study area are presented in Table 1.

Table 1: Characteristics of the Case Study

\begin{tabular}{ll}
\hline \multicolumn{1}{c}{ Title } & \multicolumn{1}{c}{ Characteristics } \\
\hline Building type and & Office, Bayero \\
location & University, Kano, \\
& Nigeria. \\
& Latitude: $12.05^{\circ} \mathrm{N}$, \\
& Longitude: $8.53^{\circ} \mathrm{E}$ \\
& Elevation: $481 \mathrm{~m}$ above \\
& sea level \\
& $3.0 \mathrm{~m}$ \\
Floor height & 0.068 \\
Occupancy (person $\left./ \mathrm{m}^{2}\right)$ & $8: 00 \mathrm{am}-4: 00 \mathrm{pm}$ \\
Office hours & \\
\hline
\end{tabular}

\section{Development of the Cooling Load Prediction Model}

\subsection{Sampling of office buildings for the study}

A convenient non-probability sampling technique was adopted for sampling the office blocks in the New Campus of BUK. The sampled office blocks selected for the study are presented in Table 2 .

Table 2: Selected Blocks with their Faculty

\begin{tabular}{lll}
\hline S/N & Block Name & Faculty \\
\hline 1 & Phase III & Agriculture \\
2 & Dean's block & $\begin{array}{l}\text { Computer Science } \\
\text { and Information } \\
\text { Techn. }\end{array}$ \\
& & Social Sciences \\
3 & Economics block & Law \\
4 & Departmental block &
\end{tabular}

3.2 Cooling load components analysis of the sampled office blocks

The architectural plans of the four selected blocks were obtained from the Physical Planning Unit (PPU) of BUK. The internal conditions of all the offices in all the four blocks selected were studied through physical inspections. Based on the pertinent information obtained from the architectural plans and physical inspection of the office blocks, the descriptive characteristics of the building were collected and presented in Table 3. 
Table 3: Descriptive Parameters of the Study Area

\begin{tabular}{llccc}
\hline S/N & Item & Maximum & Minimum & Mean \\
\hline 1 & Wall length (m) & 8.60 & 3.40 & 5.60 \\
2 & Wall width (m) & 9.45 & 2.95 & 5.00 \\
3 & Wall height (m) & 3.45 & 3.45 & 3.45 \\
4 & Window width (m) & 3.94 & 1.50 & 3.04 \\
5 & Window height (m) & 1.50 & 1.00 & 1.10 \\
6 & Wall thickness (m) & 0.27 & 0.27 & 0.27 \\
7 & Number of staff per office & 3.00 & 1.00 & 2.00 \\
8 & Number of refrigerator per office & 2.00 & 0.00 & 1.00 \\
9 & Number of lighting points per office & 4.00 & 2.00 & 3.00 \\
10 & Number of ceiling fans per office & 3.00 & 1.00 & 2.00 \\
\hline
\end{tabular}

The performance levels of the pertinent building cooling load variables were determined using the information gotten from the study area and some pertinent standard factors. Based on the data obtained, three performance levels were considered for this study as shown in Table 4.

Table 4: Performance Levels of Cooling Load Variables

\begin{tabular}{llcccc}
\hline S/N & Variable & Unit & \multicolumn{3}{c}{ Performance Level } \\
& & & $\mathbf{1}$ & $\mathbf{2}$ & $\mathbf{3}$ \\
\hline 1 & Gross floor area & $m^{2}$ & 10.03 & 28.00 & 81.27 \\
2 & Ventilation rate & $A C H$ & 0.35 & 0.425 & 0.50 \\
3 & Number of persons per office & - & 1 & 2 & 3 \\
4 & Number of lighting points per office & - & 2 & 3 & 4 \\
5 & Wattage of bulb & $W$ & 18 & 20 & 22 \\
6 & Number of ceiling fans per office & - & 1 & 2 & 3 \\
7 & The wattage of the ceiling fan & $W$ & 60 & 65 & 70 \\
8 & Number of refrigerators per office & - & 0 & 1 & 2 \\
9 & Wattage of refrigerator & $W$ & 200 & 275 & 350 \\
10 & Window area, $A_{g}$ & $m^{2}$ & 1.5 & 3.34 & 5.91 \\
11 & The volume of office, $V_{b}$ & $m^{3}$ & 34.6 & 96.6 & 280.38 \\
12 & Roof area, $A_{r}$ & $m^{2}$ & 11.582 & 33.26 & 938.39 \\
13 & Wall area, $A_{w}$ & $m^{2}$ & 11.73 & 19.32 & 32.60 \\
14 & Window-to-wall-ratio (WWR) & $\%$ & 13 & 17 & 18 \\
\hline
\end{tabular}

(a) Heat transfer through the window is the sum of the solar and conductive heat transmissions and can be determined from equation 1 .

$$
\dot{Q}_{\text {win }}=877.51 l_{g} h_{g} \text { Watts }
$$

The total heat transfer through $N_{g}$ numbers of glazing windows can be determined from equation 2 .

$$
\Rightarrow \quad \dot{Q}_{\text {win }}^{\text {total }}=877.51 l_{g} h_{g} N_{g} \quad \text { Watts }
$$

b) Heat transfer through the plane wall can be determined from equation 3 .

$$
\begin{aligned}
& \therefore \quad \dot{Q}_{\text {wall }}=24.76\left[H_{w}\left(\frac{1}{2} P_{m}-H_{w}\right)-\right. \\
& \left.N_{g} l_{g} h_{g}\right] \quad \text { Watts } \ldots \ldots \ldots \ldots \ldots \ldots \ldots \ldots \ldots \ldots \ldots \ldots \ldots \ldots \ldots \ldots \ldots \ldots \ldots \ldots
\end{aligned}
$$

c) The heat transfer through the roof can then be determined from equation (4)

$$
\therefore \quad \dot{Q}_{\text {roof }}=0.232 A_{z} \text { Watts }
$$

d) The sensible heat load of infiltration can be determined from equation 5 .

$\therefore \quad \dot{Q}_{\text {sen }}^{\text {infil }}=1.293 L_{w} W_{w} H_{w} \quad$ Watts

Similarly, the latent heat load of infiltration can be determined from equation 6 .

$\therefore \quad \dot{Q}_{\text {lat }}^{\text {infil }}=1.448 L_{w} W_{w} H_{w}$ Watts

Therefore, the total infiltration load can be determined from equation 7 .

$$
\begin{aligned}
\dot{Q}_{\text {total }}^{\text {infil }} & =\dot{Q}_{\text {sen }}^{\text {infil }}+\dot{Q}_{\text {lat }}^{\text {infil }} \\
\therefore \quad \dot{Q}_{\text {total }}^{\text {infil }} & =2.741 L_{w} W_{w} H_{w} \text { Watts }
\end{aligned}
$$

e) The sensible heat gain from occupants can be determined from equation 8 considering $Q_{s}$ being $70 \mathrm{~W}$ for an adult male [21]. This implies that: 


$$
\dot{Q}_{\text {sen }}^{p p l}=70 N_{p} \text { Watts }
$$

Similarly, the latent heat gain from occupants can be determined from equation 9 considering $Q_{l}$ being $45 \mathrm{~W}$ for an adult male [21]. This implies that:

$$
\dot{Q}_{\text {lat }}^{p p l}=45 N_{p} \quad \text { Watts }
$$

To account for the fluctuation in occupancy, a factor of 0.7 was applied. Therefore, the total heat gain from the occupants $\dot{Q}_{\text {total }}^{p p l}$ can be determined from equation 10 .

$$
\begin{aligned}
\dot{Q}_{\text {total }}^{p p l} & =0.7\left(70 N_{p}+45 N_{p}\right) \\
\therefore \quad \dot{Q}_{\text {total }}^{p p l} & =80.5 N_{p} \text { Watts } \ldots
\end{aligned}
$$

f) Heat gain from lighting $\dot{Q}_{\text {lighting }}$ can be determined from equation 11.

Table 5: Cooling Load Model Parameters

\begin{tabular}{cccccccccccc}
\hline Level & $N_{p}$ & $W_{b}$ & $P_{e}$ & $A_{r}$ & $l_{g}$ & $h_{g}$ & $N_{g}$ & $L_{w}$ & $H_{w}$ & $W_{w}$ & $P_{m}$ \\
\hline 1 & 1 & 18 & 60 & 11.58 & 1.5 & 1.5 & 2 & 3.40 & 2.8 & 2.95 & 25.1 \\
2 & 2 & 20 & 340 & 33.26 & 3.34 & 3.34 & 3 & 5.60 & 3.0 & 5.0 & 38.4 \\
3 & 3 & 22 & 770 & 938.39 & 5.91 & 5.91 & 4 & 8.60 & 3.45 & 9.45 & 60.2 \\
\hline
\end{tabular}

\subsection{Determination of cooling load components} using Taguchi analysis

Taguchi method is a universally accepted method of conducting design of experiments by using a special set of arrays called orthogonal arrays. According to [22], orthogonal array $L_{27}\left(3^{13}\right)$ should be used for 3-level factors up to 13. In this study, there are 11 factors and therefore $L_{27}\left(3^{11}\right)$ orthogonal array was used. The $L_{27}$ orthogonal array of the cooling load model parameters are presented in Table 6. g) Heat gain from equipment/appliance can be determined from equation 12 assuming the total heat gain from equipment is $P_{t}$. $\dot{Q}_{\text {equip }}=1.143 P_{t}$ Watts

Because of the usage of the equipment, the total heat gain from the use of the equipment can be determined from equation 13.

$$
\begin{aligned}
& \qquad \dot{Q}_{\text {equip }}^{\text {total }}=0.5 \times \dot{Q}_{\text {equip }} \\
& \therefore \quad \dot{Q}_{\text {equip }}^{\text {total }}=0.571 P_{t} \text { Watts } \ldots . .(13) \\
& \text { Based on the architectural information and the } \\
& \text { physical inspection carried out, the cooling load } \\
& \text { parameters considered for the model development are } \\
& \text { presented in Table 5. }
\end{aligned}
$$
(1) 
Table 6: $L_{27}$ Orthogonal Array of the Cooling load Model Parameters

\begin{tabular}{lccccccccccc}
\hline Runs & $\boldsymbol{N}_{\boldsymbol{p}}$ & $\boldsymbol{W}_{\boldsymbol{b}}$ & $\boldsymbol{P}_{\boldsymbol{e}}$ & $\boldsymbol{A}_{\boldsymbol{r}}$ & $\boldsymbol{l}_{\boldsymbol{g}}$ & $\boldsymbol{h}_{\boldsymbol{g}}$ & $\boldsymbol{N}_{\boldsymbol{g}}$ & $\boldsymbol{L}_{\boldsymbol{w}}$ & $\boldsymbol{H}_{\boldsymbol{w}}$ & $\boldsymbol{W}_{\boldsymbol{w}}$ & $\boldsymbol{P}_{\boldsymbol{m}}$ \\
\hline 1 & 1 & 18 & 60 & 11.58 & 1.00 & 1.0 & 2 & 3.4 & 2.80 & 2.95 & 25.1 \\
2 & 1 & 18 & 60 & 11.58 & 3.04 & 1.1 & 3 & 5.6 & 3.00 & 5.00 & 38.4 \\
3 & 1 & 18 & 60 & 11.58 & 3.94 & 1.5 & 4 & 8.6 & 3.45 & 9.45 & 60.2 \\
4 & 1 & 20 & 340 & 33.26 & 1.00 & 1.0 & 2 & 5.6 & 3.00 & 5.00 & 60.2 \\
5 & 1 & 20 & 340 & 33.26 & 3.04 & 1.1 & 3 & 8.6 & 3.45 & 9.45 & 25.1 \\
6 & 1 & 20 & 340 & 33.26 & 3.94 & 1.5 & 4 & 3.4 & 2.80 & 2.95 & 38.4 \\
7 & 1 & 22 & 770 & 938.39 & 1.00 & 1.0 & 2 & 8.6 & 3.45 & 9.45 & 38.4 \\
8 & 1 & 22 & 770 & 938.39 & 3.04 & 1.1 & 3 & 3.4 & 2.80 & 2.95 & 60.2 \\
9 & 1 & 22 & 770 & 938.39 & 3.94 & 1.5 & 4 & 5.6 & 3.00 & 5.00 & 25.1 \\
10 & 2 & 18 & 340 & 938.39 & 1.00 & 1.1 & 4 & 3.4 & 3.00 & 9.45 & 25.1 \\
11 & 2 & 18 & 340 & 938.39 & 3.04 & 1.5 & 2 & 5.6 & 3.45 & 2.95 & 38.4 \\
12 & 2 & 18 & 340 & 938.39 & 3.94 & 1.0 & 3 & 8.6 & 2.80 & 5.00 & 60.2 \\
13 & 2 & 20 & 770 & 11.58 & 1.00 & 1.1 & 4 & 5.6 & 3.45 & 2.95 & 60.2 \\
14 & 2 & 20 & 770 & 11.58 & 3.04 & 1.5 & 2 & 8.6 & 2.80 & 5.00 & 25.1 \\
15 & 2 & 20 & 770 & 11.58 & 3.94 & 1.0 & 3 & 3.4 & 3.00 & 9.45 & 38.4 \\
16 & 2 & 22 & 60 & 33.26 & 1.00 & 1.1 & 4 & 8.6 & 2.80 & 5.00 & 38.4 \\
17 & 2 & 22 & 60 & 33.26 & 3.04 & 1.5 & 2 & 3.4 & 3.00 & 9.45 & 60.2 \\
18 & 2 & 22 & 60 & 33.26 & 3.94 & 1.0 & 3 & 5.6 & 3.45 & 2.95 & 25.1 \\
19 & 3 & 18 & 770 & 33.26 & 1.00 & 1.5 & 3 & 3.4 & 3.45 & 5.00 & 25.1 \\
20 & 3 & 18 & 770 & 33.26 & 3.04 & 1.0 & 4 & 5.6 & 2.80 & 9.45 & 38.4 \\
21 & 3 & 18 & 770 & 33.26 & 3.94 & 1.1 & 2 & 8.6 & 3.00 & 2.95 & 60.2 \\
22 & 3 & 20 & 60 & 938.39 & 1.00 & 1.5 & 3 & 5.6 & 2.80 & 9.45 & 60.2 \\
23 & 3 & 20 & 60 & 938.39 & 3.04 & 1.0 & 4 & 8.6 & 3.00 & 2.95 & 25.1 \\
24 & 3 & 20 & 60 & 938.39 & 3.94 & 1.1 & 2 & 3.4 & 3.45 & 5.00 & 38.4 \\
25 & 3 & 22 & 340 & 11.58 & 1.00 & 1.5 & 3 & 8.6 & 3.00 & 2.95 & 38.4 \\
26 & 3 & 22 & 340 & 11.58 & 3.04 & 1.0 & 4 & 3.4 & 3.45 & 5.00 & 60.2 \\
27 & 3 & 22 & 340 & 11.58 & 3.94 & 1.1 & 2 & 5.6 & 2.80 & 9.45 & 25.1 \\
\hline
\end{tabular}


The $L_{27}$ orthogonal array of the cooling load model parameters and the corresponding computed cooling load components are presented in Table 7 .

Table 7: $L_{27}$ Orthogonal Array of Cooling Load Model Parameters and Cooling Load Components

\begin{tabular}{|c|c|c|c|c|c|c|c|c|c|c|c|c|c|c|c|c|c|c|c|}
\hline \multirow[t]{2}{*}{ Runs } & \multicolumn{11}{|c|}{ Cooling load model parameters } & \multicolumn{7}{|c|}{ Cooling load components } & \multirow{2}{*}{$\begin{array}{c}\text { Total } \\
\text { cooling load } \\
\text { (Y) } \\
(W)\end{array}$} \\
\hline & $N_{p}$ & $\begin{array}{c}W_{b} \\
(W)\end{array}$ & $\begin{array}{c}P_{e} \\
(W)\end{array}$ & $\begin{array}{c}A_{r} \\
\left(m^{2}\right)\end{array}$ & $\begin{array}{c}l_{g} \\
(m)\end{array}$ & $\begin{array}{c}h_{g} \\
(m)\end{array}$ & $N_{g}$ & $\begin{array}{c}L_{w} \\
(m)\end{array}$ & $\begin{array}{l}H_{w} \\
(m)\end{array}$ & $\begin{array}{l}W_{w} \\
(m)\end{array}$ & $\begin{array}{l}P_{m} \\
(m\end{array}$ & $\begin{array}{c}Q_{p} \\
(W)\end{array}$ & $\begin{array}{c}Q_{l} \\
(W)\end{array}$ & $\begin{array}{c}Q_{e} \\
(W)\end{array}$ & $\begin{array}{c}Q_{r} \\
(W)\end{array}$ & $\begin{array}{c}Q_{W} \\
(W)\end{array}$ & $\begin{array}{l}Q_{\text {win }} \\
(W)\end{array}$ & $\begin{array}{c}Q_{i n} \\
(W)\end{array}$ & \\
\hline 1 & 1 & 18 & 60 & 11.58 & 1.00 & 1.0 & 2 & 3.4 & 2.80 & 2.95 & 25.1 & 80.5 & 12.96 & 34.26 & 2.68 & 626.43 & 1350.36 & 76.99 & 2184.17 \\
\hline 2 & 1 & 18 & 60 & 11.58 & 3.04 & 1.1 & 3 & 5.6 & 3.00 & 5.00 & 38.4 & 80.5 & 12.96 & 34.26 & 2.68 & 954.94 & 6773.41 & 230.24 & 8089 \\
\hline 3 & 1 & 18 & 60 & 11.58 & 3.94 & 1.5 & 4 & 8.6 & 3.45 & 9.45 & 60.2 & 80.5 & 12.96 & 34.26 & 2.68 & 1691.17 & 15961.26 & 768.53 & 18551.36 \\
\hline 4 & 1 & 20 & 340 & 33.26 & 1.00 & 1.0 & 2 & 5.6 & 3.00 & 5.00 & 60.2 & 80.5 & 14.4 & 194.14 & 7.72 & 1963.47 & 1350.36 & 230.24 & 3840.83 \\
\hline 5 & 1 & 20 & 340 & 33.26 & 3.04 & 1.1 & 3 & 8.6 & 3.45 & 9.45 & 25.1 & 80.5 & 14.4 & 194.14 & 7.72 & 528.95 & 6773.41 & 768.53 & 8367.64 \\
\hline 6 & 1 & 20 & 340 & 33.26 & 3.94 & 1.5 & 4 & 3.4 & 2.80 & 2.95 & 38.4 & 80.5 & 14.4 & 194.14 & 7.72 & 551.65 & 15961.26 & 76.98 & 16886.64 \\
\hline 7 & 1 & 22 & 770 & 938.39 & 1.00 & 1.0 & 2 & 8.6 & 3.45 & 9.45 & 38.4 & 80.5 & 15.84 & 439.67 & 217.71 & 1295.88 & 1350.36 & 768.53 & 4168.48 \\
\hline 8 & 1 & 22 & 770 & 938.39 & 3.04 & 1.1 & 3 & 3.4 & 2.80 & 2.95 & 60.2 & 80.5 & 15.84 & 439.67 & 217.71 & 1644.26 & 6773.41 & 76.98 & 9248.36 \\
\hline 9 & 1 & 22 & 770 & 938.39 & 3.94 & 1.5 & 4 & 5.6 & 3.00 & 5.00 & 25.1 & 80.5 & 15.84 & 439.67 & 217.71 & 124.05 & 15961.26 & 230.24 & 17069.26 \\
\hline 10 & 2 & 18 & 340 & 938.39 & 1.00 & 1.1 & 4 & 3.4 & 3.00 & 9.45 & 25.1 & 161 & 12.96 & 194.14 & 217.71 & 600.43 & 2970.79 & 264.21 & 4421.23 \\
\hline 11 & 2 & 18 & 340 & 938.39 & 3.04 & 1.5 & 2 & 5.6 & 3.45 & 2.95 & 38.4 & 161 & 12.96 & 194.14 & 217.71 & 1119.59 & 6157.64 & 156.22 & 8019.25 \\
\hline 12 & 2 & 18 & 340 & 938.39 & 3.94 & 1.0 & 3 & 8.6 & 2.80 & 5.00 & 60.2 & 161 & 12.96 & 194.14 & 217.71 & 1599.99 & 7980.63 & 330.02 & 10496.44 \\
\hline 13 & 2 & 20 & 770 & 11.58 & 1.00 & 1.1 & 4 & 5.6 & 3.45 & 2.95 & 60.2 & 161 & 14.4 & 439.67 & 2.69 & 2167.55 & 2970.79 & 156.22 & 5912.32 \\
\hline 14 & 2 & 20 & 770 & 11.58 & 3.04 & 1.5 & 2 & 8.6 & 2.80 & 5.00 & 25.1 & 161 & 14.4 & 439.67 & 2.69 & 450.14 & 6157.64 & 330.02 & 7555.55 \\
\hline 15 & 2 & 20 & 770 & 11.58 & 3.94 & 1.0 & 3 & 3.4 & 3.00 & 9.45 & 38.4 & 161 & 14.4 & 439.67 & 2.69 & 910.67 & 7980.63 & 264.21 & 9773.26 \\
\hline 16 & 2 & 22 & 60 & 33.26 & 1.00 & 1.1 & 4 & 8.6 & 2.80 & 5.00 & 38.4 & 161 & 15.84 & 34.26 & 7.72 & 1028.04 & 2970.79 & 330.02 & 4547.66 \\
\hline 17 & 2 & 22 & 60 & 33.26 & 3.04 & 1.5 & 2 & 3.4 & 3.00 & 9.45 & 60.2 & 161 & 15.84 & 34.26 & 7.72 & 1787.18 & 6157.64 & 264.21 & 8427.84 \\
\hline 18 & 2 & 22 & 60 & 33.26 & 3.94 & 1.0 & 3 & 5.6 & 3.45 & 2.95 & 25.1 & 161 & 15.84 & 34.26 & 7.72 & 484.68 & 7980.63 & 156.22 & 8840.34 \\
\hline 19 & 3 & 18 & 770 & 33.26 & 1.00 & 1.5 & 3 & 3.4 & 3.45 & 5.00 & 25.1 & 241.5 & 12.96 & 439.67 & 7.72 & 665.92 & 3038.31 & 160.76 & 4566.84 \\
\hline 20 & 3 & 18 & 770 & 33.26 & 3.04 & 1.0 & 4 & 5.6 & 2.80 & 9.45 & 38.4 & 241.5 & 12.96 & 439.67 & 7.72 & 835.89 & 8210.19 & 406.15 & 10154.08 \\
\hline 21 & 3 & 18 & 770 & 33.26 & 3.94 & 1.1 & 2 & 8.6 & 3.00 & 2.95 & 60.2 & 241.5 & 12.96 & 439.67 & 7.72 & 1798.37 & 5852.46 & 208.62 & 8561.29 \\
\hline 22 & 3 & 20 & 60 & 938.39 & 1.00 & 1.5 & 3 & 5.6 & 2.80 & 9.45 & 60.2 & 241.5 & 14.4 & 34.26 & 217.71 & 1781.23 & 3038.31 & 406.15 & 5733.56 \\
\hline 23 & 3 & 20 & 60 & 938.39 & 3.04 & 1.0 & 4 & 8.6 & 3.00 & 2.95 & 25.1 & 241.5 & 14.4 & 34.26 & 217.71 & 408.29 & 8210.19 & 208.62 & 9334.97 \\
\hline 24 & 3 & 20 & 60 & 938.39 & 3.94 & 1.1 & 2 & 3.4 & 3.45 & 5.00 & 38.4 & 241.5 & 14.4 & 34.26 & 217.71 & 1130.78 & 5852.46 & 160.76 & 7651.86 \\
\hline 25 & 3 & 22 & 340 & 11.58 & 1.00 & 1.5 & 3 & 8.6 & 3.00 & 2.95 & 38.4 & 241.5 & 15.84 & 194.14 & 2.69 & 1091.92 & 3038.31 & 208.62 & 4793.01 \\
\hline 26 & 3 & 22 & 340 & 11.58 & 3.04 & 1.0 & 4 & 3.4 & 3.45 & 5.00 & 60.2 & 241.5 & 15.84 & 194.14 & 2.69 & 1975.42 & 8210.19 & 160.76 & 10800.53 \\
\hline 27 & 3 & 22 & 340 & 11.58 & 3.94 & 1.1 & 2 & 5.6 & 2.80 & 9.45 & 25.1 & 241.5 & 15.84 & 194.14 & 2.69 & 461.33 & 5852.46 & 406.15 & 7174.11 \\
\hline
\end{tabular}


3.4

In order to develop the cooling load model, from Table 3.10 , the total cooling load $(Y)$ was regressed against the cooling load model parameters $N_{p}, W_{b}, P_{e}, A_{r}$, $l_{g}, h_{g}, N_{g} L_{w}, H_{w}, W_{w}$, and $P_{m}$ using multiple linear regression technique run on Minitab 19 software. The regression analysis output presented in Table 8 shows that the P-values of the parameters $W_{b}, P_{e}, A_{r}, L_{w}, H_{w}$, and $W_{w}$ were greater than 0.05 therefore, they were not considered for the model development.

Table 8: Regression Analysis Output for Cooling Load Model

\begin{tabular}{ccccc}
\hline Training & Cooling Load Parameter & P-Value & VIF & $\boldsymbol{R}^{2}$ Value (\%) \\
\hline & $N_{p}$ & 0.001 & 1.00 & \\
$W_{b}$ & 0.997 & 1.00 & \\
First Model Training & $P_{e}$ & 0.584 & 1.00 & \\
& $A_{r}$ & 0.780 & 1.00 & \\
& $l_{g}$ & 0.000 & 1.00 & 94.95 \\
& $h_{g}$ & 0.000 & 1.00 & \\
& $N_{g}$ & 0.000 & 1.00 & \\
& $L_{w}$ & 0.715 & 1.00 & \\
Second Model Training & $H_{w}$ & 0.643 & 1.00 & \\
& $W_{w}$ & 0.645 & 1.00 & \\
& $P_{m}$ & 0.084 & 1.00 & \\
& $N_{p}$ & 0.000 & 1.00 & \\
& $l_{g}$ & 0.000 & 1.00 & \\
& $h_{g}$ & 0.000 & 1.00 & \\
\hline
\end{tabular}

The cooling load was again regressed against the remaining parameters and the improved cooling load model developed is given in equation 3.48 and the
Pareto chart of the standardized effects of the parameters in the improved model is shown in Fig. 1.

$$
Y=-14486-1440 N_{p}+3150 l_{g}+7455 h_{g}+2916 N_{g}+38.2 P_{m}
$$

\subsection{Performance of the cooling load prediction model}

ANOVA was employed to determine the performance of the model developed. Therefore, coefficient of determination $R^{2}$ was used to determine the association between the dependent variable (cooling load) and the independent variables (cooling load parameters). The $R^{2}$ value was determined to be $94.62 \%$ as shown in Table 8 . This implies that $94.62 \%$ variation in the cooling load $(Y)$ could be explained by the cooling load parameters $N_{p}, l_{g}, h_{g}, N_{g}$, and $P_{m}$.

Variance Inflation Factor (VIF) was used to check the severity of multicollinearity. VIF less than 5 as shown in Table 8 for all the independent parameters shows that there is no multicollinearity. The ANOVA results summarized and presented in Table 8 show that the mathematical correlation of the building cooling load is statistically significant at $95 \%$ confidence level.

\subsection{Estimation of the Cooling Load of the Site Office Building}

ISSN (Print): 2456-6411 | ISSN (Online): 2456-6403
The cooling load model developed was used to estimate the cooling load of the site office building with the cooling load parameters presented in Table 9.

Table 9: Values of the Cooling Load Predictor Parameters

\begin{tabular}{|c|c|c|}
\hline S/N & $\begin{array}{c}\text { Cooling Load } \\
\text { Parameter }\end{array}$ & Value \\
\hline 1 & $N_{p}$ & 2.000 \\
\hline 2 & $l_{g}$ & $1.831 \mathrm{~m}$ \\
\hline 3 & $h_{g}$ & $1.222 \mathrm{~m}$ \\
\hline 4 & $N_{g}$ & 4.000 \\
\hline 5 & $P_{m}$ & $34.880 \mathrm{~m}$ \\
\hline
\end{tabular}

Substituting the pertinent information aforementioned into the cooling load model given in equation 3.55 yields:

$$
\begin{aligned}
Y=-14486- & 1440(2)+3150(1.831) \\
& +7455(1.222)+2916(4) \\
& +38.2(34.88) \\
\therefore \quad Y=10477.52 W & \approx 10.48 \mathrm{~kW}
\end{aligned}
$$

287 JREAS, Vol. 07, Issue 01, Jan 22 


\subsection{Validation of the Cooling Load Prediction Model}

The building model of the site office building was created using DesignBuilder software as shown n Fig. 1. The cooling load of the site office model was the determined using EnergyPlus thermal simulation

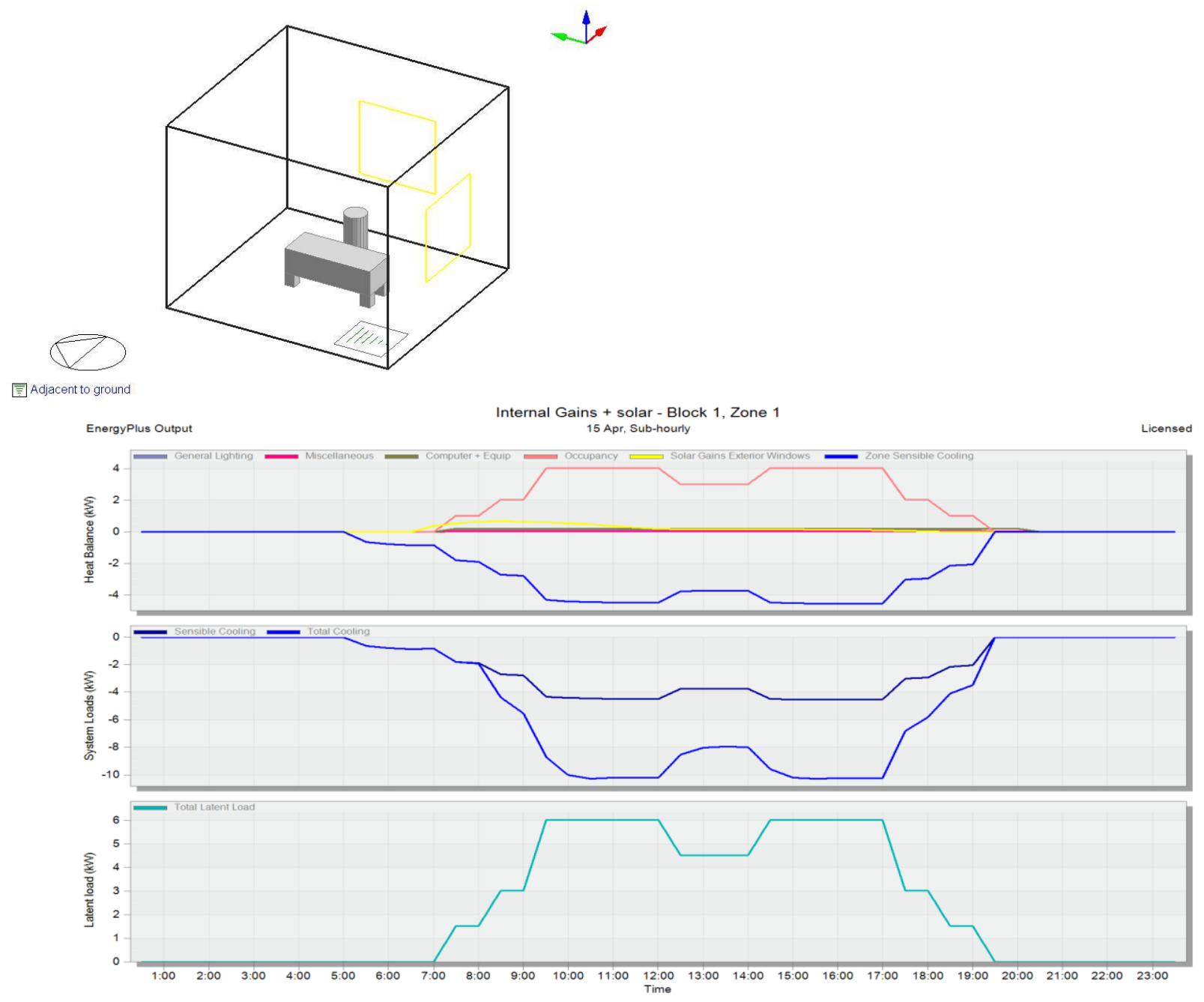

Figure 2: Computed Cooling Load using EnergyPlus

The RMSLE between the predicted and the simulated cooling loads is 0.017 .

\section{DISCUSSION}

The cooling load prediction model parameters were statistically significant for predicting the building cooling loads since their P-values are less than 0.05 as presented in Table 4. The VIF for the model parameters are all less than 5.0 as shown in Table 8. This indicates that there is complete absence of the effect of multicollinearity in the model developed. This is in concordance with the work of Kaushik et al. (2020) who stated that VIF of less than 5.0 does not indicate high correlation among the independent variables and hence, no measure is required to remove the
Figure 1. 3D Model of the Site Office Building

The cooling load determined using EnergyPlus was $10.29 \mathrm{~kW}$ as shown on the EnergyPlus output in Fig. 2. collinearity. The value of $R^{2}$ of $94.62 \%$ as shown in Table 8 implies that the developed prediction model has high inference power, meaning that $94.62 \%$ variation of the predicted cooling load could be explained by the cooling load model parameters. Employing the cooling load model, the cooling load of the site office building was $10.48 \mathrm{Kw}$ while the EnergyPlus simulated result was $10.29 \mathrm{Kw}$ as displayed on the system load in Fig. 2. The RMSLE between the predicted and the EnergyPlus simulated result is 0.017 which indicates that the model developed has high predictive power.

\section{CONCLUSION}

In this study, a cooling load model was developed for the purpose of estimating the cooling load of office buildings in the New Campus of Bayero University 
Kano, Nigeria. The performance of the model developed is high with respect to the P-value and the VIF of the cooling load model parameters. The low value of the RMSLE between the predicted and the simulated results portrays the high accuracy of the cooling load model developed. Therefore, this proposed model could reliably be used to predict the cooling load of office buildings in the New Campus of Bayero University Kano and, also, in any other building with similar attributes.

\section{REFERENCES}

[1] S. Kim, P. Zadeh, S. Staub-French, T. Froece, \& B. Cavka, "Assessment of the Impact of Window Size, Position and Orientation of Building Energy Load using BIM", International Conference on Sustainable Design, Engineering and Construction, 2016, 1324-1332.

[2] V. Ravat, S. Shivakar, D. Biplab, \& B. Sel, "Effect of Orientation of Window on Building Heat Load: Perspective of N-E India", Material Science and Engineering. India: IOP Conference, 2017.

[3] Y. Sun, W. Yupeng, \& R. Wilson, "A Review of Thermal and Optical Characteristics of Complex Window Systems and their Building Performance Prediction", Applied Energy, 2018, 729-742.

[4] C. Koranteng, C. Essel, \& J. Nkrumah, "Paaive Analysis of the Effect of Window Size and Position on Indoor Comfort for Residential Rooms in Kumasi, Ghana", International Advanced Research Journal in Science, Engineering and Technology, 2(10), 2015, 114-120.

[5] H. Hashim, E. Sokolova, O. Derevianko, \& D. Solovev, (2018). "Cooling Loads Calculations", International MultiConference on Industrial Engineering in Modern Technologies, 463, 2018, 1-6. doi:10.1088/1757$899 x / 463 / 3 / 032030$

[6] N. Obuka, D. Utazi, P. Onyechi, N. Okoli, \& C. Ene, "Determination of Nonresidential Space Cooling Load: Vb Program Application", International Journal of Scientific and Technology Research, 4(01), 2015.

[7] D. Yan, Z. Qiang, Y. Tianhao, \& Y. Fan, "Effect of Input Variables on Cooling Load Prediction Accuracy of an Office Building", Applied Thermal Engineering, 2017. Retrieved from http://dx.doi.org/10.1016/j.applthermaleng.2017.09.007

[8] S. Simon, K. Richard, \& W. Eric, "An Intelligent Approach to Assessing the Effect of Building Occupancy on Building Cooling Load Prediction", Building and

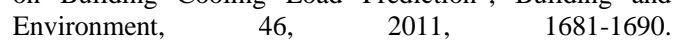
doi:10.1016/j.buildenv.2011.02.008

[9] H. Chen, C. Jiao, L. Zheifen, Z. Qianru, \& C. Yezan, "Solving Model of Temperature and Humidity Profiles in Spray Cooling", Building and Environment, 123, 2017, 189-199. http://dx.doi.org/10.1016/j.buildenv.2017.06.043

[10] K. Siyue, G. Guangeai, H. Tianhe, \& and W. Rong, "A Simplified Method for Building Cooling Load Calculations", ICSDEC, 2013

[11] G. Qiang, T. Zhe, D. Yan, \& Z. Neng, "An Improved Office Building Cooling Load Prediction Model based on Multivariable Linear Regression", Energy and Buildings,
107, 2015 ,

http://dx.doi.org/10.1016/j.enbuild.2015.08.041

445-455.

[12] F. Chengliang, I. Yundan, \& Yunfei, D. "Development of a Cooling Load Prediction Model for Air Conditioning System Control of Office Buildings", International Lowcarbon Technologies, 14(1), 2019, 70-75. http://doi.org/10.1093/ijlct/cty057

[13] C. Joseph, K. Kevia, L. Dalong, \& C. Tsang, "Multiple Linear Regression Models for Energy Use in Air Conditioned Office Buildings in different Climates", Energy Conversion and Management, 2010, 2692-2697. doi:10.1016/j.proeng.2015.08.495

J. Hae, \& K. Eon, "Development of Heating and Cooling Loads Equations for Office Buildings in Korea", Journal of Asian Architecture and Building Engineering, 13(2), 2014, 437-445.

[15] A. Mohammad, "Assessment of Passive Downdraft Evaporative Cooling Technique for Environmental Sustainability in Buildings", International Journal of Research in Chemical, Metallurgical and Civil Engineering, 3, 2016, 326-330. http://doi.org/10.15242/IJRCMCE.U1016309

[16] A. Maged, F., Joseph, \& R. Ranji, (2015). "An Enhanced Linear Regression-based Building Energy Model (LRBEM+) for Early Design", Journal of Building Performance $\quad 2015$. http://dx.doi.org/10.1080/19401473.2015.1004108

[17] Z. Chaoba, Z. Yang, Z. Xuejun, F. Cheng, \& L. Tingting, (2017). "An Improved Cooling Load Prediction Method for Buildings with the Estimation of Prediction Interval", 10th International Symposium on Heating, Ventilation and Air Conditioning. 205,2017, 2422-2428. Jinan, China. doi:10.1016/j.proeng.2017.09.967

[18] G. Devindi, \& R. Thanuja, "A Model for Estimating Cooling Energy Demand at Early Design Stage of Condominiums in Sri Lanka", Journal of Building Engineering. https://doi.org/10.1016/j.jobe.2018.01.011

[19] A. Navid, K. Georgios, D. Daniel, \& M. Timothy, "Linear Regression Models for Prediction of Annual Heating and Cooling Demand in Representative Australian Residential Dwellings", International Conference on Improving Residential Energy Efficiency, 121, 2017, 79-86. doi:10.1016/j.egypro.2017.07.482

[20] J. Zhao, \& X. Liu, "A Hybrid Method of dynamic Cooling and Heating Load Forecasting for Office Buildings based on Artificial Intelligence and Regression Analysis", Energy and Building, 2018, Doi: 10.1016/j.ebuild.2018.06.050

[21] ASHRAE-55, Thermal Environmental Condition for Human Occupancy. Atlanta: American Society of Heating, Refrigeration and Air Conditioning Engineers, 2010

[22] G. Taguchi, \& Y. Yokoyama, Taguchi Method: design of experiment. Amer Supplier Inst., 1993

[23] A. Kaushik, A. Mohammed, P., Tumula, \& J. Ebohon, "Effect of Thermal Comfort on Occupant Productivity in Office Buildings: Response Surface Analysis", Building and Environment, 2020, https://doi.org/10.1016/j.buildenv.2020.107021 